\title{
The Role of Matrix Metalloproteinase-2 Expression in Gastric Cancer Susceptibility: A Systematic Review
}

\author{
Fereshte Bibak (iD) ${ }^{1}$, Samane Ahmadi $\mathbb{B}^{1}{ }^{1}$, Zeynab Khateri ${ }^{(\mathbb{B})}{ }^{1}$, Amirhossein Ahmadi ${ }^{1}{ }^{1}$ and Kheirollah \\ Yari (iiD), ${ }^{2}$ \\ ${ }^{1}$ Students Research Committee, Kermanshah University of Medical Sciences, Kermanshah, Iran \\ ${ }^{2}$ Medical Biology Research Center, Health Technology Institute, Kermanshah University of Medical Sciences, Kermanshah, Iran \\ "Corresponding author: Assistant Professor of Biomedicine, Medical Biology Research Center, Medical School, Daneshgah Avenue, Kermanshah, Iran. Tel: +98-8334279923 Fax: \\ +98-8334276471, Email: khirollah.yari@yahoo.com
}

Received 2019 May 21; Revised 2019 July 25; Accepted 2019 July 29.

\begin{abstract}
Context: Gastric carcinoma (GC) is the most commonly diagnosed cancer that has been one of the main causes of cancer death worldwide. The matrix metalloproteinase-2 (MMP2) gene was expressed in the gastric cancer tissues compared to the matched normal tissues that are associated with the metastasis of gastric cancer cells.

Objectives: This systematic review was performed to investigate the role of MMP-2 in gastric cancer among the different population. Evidence Acquisition: We searched on electronic databases such as PubMed, Scopus, Science Direct and Cochrane Library Database without any language restriction for relevant publications which were published until April 2019.

Results: Thirty two original and relevant studies that evaluate the association between gastric cancer and MMP-2 were included. This systematic review indicated that increased MMP-2 expression has been seen in gastric cancer. MMP-2 over-expression may play a crucial role in degrading extracellular matrix as well as stimulate angiogenesis.

Conclusions: MMP2 over-expression can play a critical role in tumor metastasis, tumor size, invasion, and lymph node invasion in GC.
\end{abstract}

Keywords: Gastric Cancer, Matrix Metalloproteinases-2, Systematic Review

\section{Context}

Gastric cancer (GC) is one of the most common malignancies (4th in men and 7th in women) with over one million new cases in 2018. In addition, GC includes about 10\% of the new diagnoses of cancer cases and comprises $12 \%$ of the overall cancer-related deaths in the world (1). Based on reported data, GC is the 5th common carcinoma in men and women among developed countries and has the second rank for men individual in numerous countries of Asia and South America (2). However, due to the recognition of certain risk factors for susceptibility to GC, the worldwide morbidity and mortality rate has declined over the past few decades, but there is still a high prevalence of gastric cancer in some population in developing countries $(3,4)$. GC is a multi-factorial disease that its carcinogenesis mechanisms are still unknown. Based on previous epidemiological studies, the interplay of both genetic and environmental factors (such as age, sex, body mass index, infectious agents, diet, and lifestyle) play a major role in the gastric carcinogenesis that can be different among ethnic groups
(5-7). Different genes are involved in variety of processes such as inflammatory response, DNA repair, cell proliferation, carcinogen detoxification, and antioxidant protection to development and susceptibility of gastric cancer and increase invasive progression and metastasis $(8,9)$.

Matrix metalloproteinases (MMPs), the main family of zinc-dependent enzymes, play an important role in the digestion of the extracellular matrix (ECM) (10). Furthermore, different studies have shown that MMPs affect cancer development processes such as apoptosis, cell proliferation, and immune system (11).

So far 24 different types of MMPs have been reported and 23 of them had been found in human (12). However, MMPs present in healthy individuals, but they are upregulated in almost all types of cancer $(13,14)$. The high expression of different MMP genes has been correlated to metastasis, invasion, and survival of many human cancers (14). These MMPs are gelatinases, stromelysins, membranetype MMPs, and other MMPs. Cells synthesize MMPs as an inactive zymogen and the N-terminal cleavage of propeptide leads to make them activated. Based on the re- 
ported of previous studies, 4 members of this family are associated-MMPs with GC, MMP-1, -2, -7, and-9. The roles of MMP-2 (gelatinase A with $72 \mathrm{kDa}$ ) and MMP-9 (gelatinase B with $92 \mathrm{kDa}$ ) are more important than others in tumor invasion and metastasis, this importance is because of their substrates (11). MMP-2 and MMP-9 digest types IV and V of collagen, fibronectin and gelatin. The basement membrane is the first barrier for a metastatic epithelial tumor that consists of type IV collagen (15).

Among main MMPs genes related to cancer development, more attention has been focused on the Matrix metalloproteinase 2 which is over-expressed in the different human tumors. Expression level and activity of MMP-2 are often associated with invasion, cell migration, and development of tumor cells (16). Known evidence indicates that MMPs, especially MMP-2, play a critical function in the degradation of ECM that are mediated by tumor cells. MMP-2 gene with a total length of $27 \mathrm{kbs}$ is located on chromosome 16q21 and contains 12 introns and 13 exons (17). Over-expression of MMP-2 gene was reported to the GC tissues compared to the matched normal tissues that are correlated to the invasion and metastasis in GC cells (12).

\section{Objectives}

According to the evidence available on this issue, the present study aimed to conduct a review article of all original studies that have investigated the role of MMP-2 in gastric cancer among different population.

\section{Methods}

\subsection{Search Strategy}

We searched on electronic databases such as PubMed, Scopus, Science Direct, and Cochrane Library Database without any language restriction for relevant publications that were published until April 2019. In addition, following keywords and abbreviation terms were used in the search strategy to get relevant results: ["gastric cancer", "gastric carcinoma”, "GC”, "stomach carcinomas" or "stomach cancer"] and ["matrix metalloproteinase 2", "MMP-2", "MMP2", “72kDa Type IV Collagenase”, "matrix metalloproteinase2" or "MMP2metalloproteinase"].

\subsection{Selection Criteria}

The criteria for the selection of relevant studies were: (1) the article type must be original research that focused on the association of MMP2 expression in GC patients, (2) all studies must have used human specimens, (3) full-text article must be in English language, and (4) the study must give suitable data about the genetic, expression levels or activity of the MMP2.

\subsection{Data Extraction}

The required information from the included study was extracted using a standardized form. We documented the most relevant information such as the first author's name, publication year, publication Journal, geographical location, sample characteristics (size, sex, age, and type), subject or aim, used method, and main results that state the association between expression levels of $M M P$-2 and gastric cancer.

\section{Results and Discussion}

This systematic review study indicated the role of MMP2 expression in gastric cancer susceptibility. Primarily, the highly sensitive search strategy recognized 152 articles. We reviewed all articles according to the inclusion and exclusion criteria (Figure 1). Finally, 32 original and relevant studies which had evaluated the association between gastric cancer and MMP-2 were selected. The articles were published between 1996 and 2019 (Table 1).

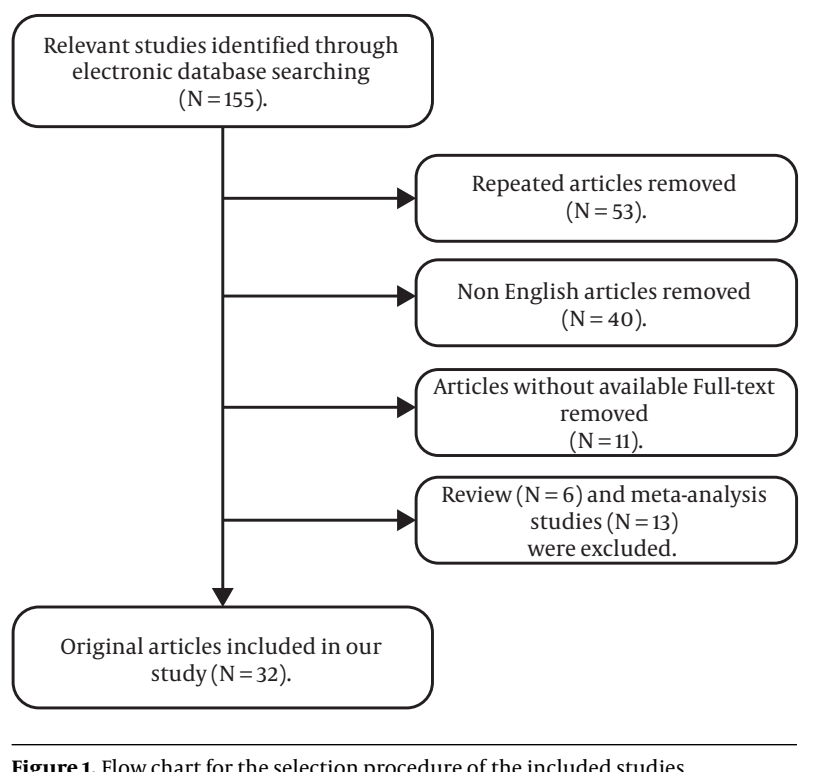

Figure 1. Flow chart for the selection procedure of the included studies

The total of 32 articles were included to be reviewed. The most of the population studied in these papers were from China (14 articles: 47\%) and other studies were from Poland (5 articles), Germany (4 articles), Japan (3 articles), Netherlands ( 2 articles), Taiwan ( 2 articles), Finland (1 article), and Italy (1 article). Since the gastric cancer rate in the countries of East Asia and then in Eastern and Central Europe is higher than in other countries or parts of the world (47), therefore most of the studies have been reported from these countries. 
Among 32 included articles, the total number of studied samples were 5661 individuals, among these cases, 3709 individuals were patients with gastric cancer and 2318 individuals were considered as controls. All available data such as mean age, sex status (male/female ratio), and sample types are presented in Table 1 . Based on the obtained data from reported articles, study specimens were tissue (N:24), blood (N: 5), tissue and blood (N:2) and, lymph node (N:1).

These samples were used to study MMP-2 expression (25 cases), MMP-2 expression and immunoreactivity (2 cases), MMP-2 expression and polymorphism (1 case), serum level analysis of MMP-2 (2 cases), and polymorphism (2 cases).

In each research, several methods have been used to reach the mentioned aims, and the IHC method has been used more than others. Accordingly, the most used method in the reviewed articles was the IHC method (19 cases) and then RT-PCR (9 cases ), Gelatin Zymography (6 cases), ELISA ( 4 cases), PCR-RFLP (1 case), PCR-direct sequencing (1 case), RNA/DNA calculator with spectrophotometric (1 case), Tissue Microarray (TMA) (1 case), Immunostaining (1case), Sandwich enzyme immunoassay (1 case), PCR Based DHPLC analysis and DNA sequencing (1 case).

The analysis of the present study showed that the expression of MMP-2 in the cancer subjects was mostly higher than control individuals. However, according to the study by Mroczko et al. 2011, the serum level of MMP-2 gene was positively lower in GC patients than healthy individuals (29). Consistent with results of Mroczko et al. (29) 2011 and Lukaszewicz-Zajac et al. (26) 2013 that serum level of MMP-2 was significantly lower in GC patients. In addition, according to Emara et al. 2009, MMP-2 level was not significantly higher in GC patients than controls individuals (15).

Based on the findings of the present study, more than $50 \%$ of reported studies showed that abnormal changes in MMP-2 expression play a critical role in tumor metastasis in GC. In addition, 8 studies examined the role of MMP- 2 in the tumor invasion and resulted that MMP-2 expression significantly correlated with tumor invasion (Table 1). Further, Bornschein et al. showed that MMP-2 had a higher expression level in the invasive front compared to the center section of the tumor (23). These findings support the hypothesis that over-expression of MMP-2 gene may play a crucial role in degrading type IV Collagen, gelatin, and laminin in basal membrane and other components of extracellular matrices, which is a vital step toward the development, invasion, and tumor metastasis. Additionally, the results of the other study by Zheng et al. showed that IL- $1 \beta$ could activate p38 and increase gastric adenocarcinoma (GA) cell migration and invasion (35). IL-1 $\beta$ - induced GA cell migration and invasion occur via activation of the 38 signaling pathway which leads to AP-1 activation and up-regulation of MMP-2.
Zheng et al. (35) and Partyka et al. (28) investigated the correlation between vascular endothelial growth factor (VEGF) and MMP-2 in cancerous tissue of metastatic patients. They found that MMP-2 and VEGF were positively associated with the tumor size, depth of invasion, lymphatic, and venous metastasis. Regarding their results, MMP-2 plays an important role in the "angiogenic switch" and tumor cells can synthesize and secrete high levels of MMP-2 paracrine and/or autocrine to stimulate angiogenesis and increase VEGF release (35).

In the other study, Chen et al., examined how JWA, a multifunctional microtubule-binding protein regulates GC angiogenesis via MMP-2 and the role of JWA and MMP-2 in the progression and prognosis of GC. JWA inhibits GC angiogenesis via Sp1-mediated MMP-2 expression. Sp1 was the transcription factor of MMP-2; it has been reported that Sp1 up-regulates the MMP-2 gene in cancers and promotes angiogenesis in GC (24).

Ten studies surveyed the MMP-2 expression and its effect on prognosis in GC patients. Among these, Donizy et al. (22), Lukaszewicz-Zajac et al. (26), Kubben et al. (37), Ji et al. (39), and Caenazzo et al (43) suggested the high expression of MMP-2 as an independent and molecular prognostic factor for gastric cancer. However, the other authors had a different idea, they declared that MMP-2 alone was not enough and suggested other molecules to accompany MMP-2 as a prognostic factor. According to the findings of other research by Yao et al. (21) and Ji et al. (39) MMP-9 was as a helpful factor along with MMP2. Also, Allgayer et al. suggested that consideration of interrelated tumor-associated proteases like uPA receptor in combination with MMP-2 may improve its prognostic power (42). The results of Wang et al. showed the evaluation of both telomerase activity (TA) and MMP2 protein can more effectively detect patients who are susceptible to disease recurrence and prognosis (27). As mentioned above, Chen et al. findings pointed out that JWA and MMP-2 may serve as prognostic biomarkers in GC (24).

Survey of MMP-2-1306 C/T polymorphism which reported by Miao et al. (13), Zhang et al. (17), and Wu et al. (33) proved that this SNP correlated with GC susceptibility, lymphatic or venous invasion, and progression of gastric cancer but not associated with the tumor diameter, the depth of tissue infiltration, lymphatic metastasis, survival rate, age, sex, H. pylori infection, Lauren's classification, tumor status, depth of invasion or lymph node metastasis, and metastasis of GCA (Gastric Cardia Adenocarcinoma). Miao et al. indicated that MMP-2-1306 C/T polymorphism is associated with the risk of gastric cancer development (13), but this result is not consistent with Wu et al. (33). In the study carried out by Zhang et al. showed that susceptibility of GC for patients with CC+CT genotype in MMP-2-1306 C/T 
SNP was 1.803 times more than the individuals who have TT genotype (17), and Miao et al. proved it in their study too (13). However, Wu et al. reported that the $\mathrm{C} / \mathrm{T}$ allele frequencies of MMP-2-1306 in GC patients did not differ from those of controls. In addition in the other study conducted by Wu et al. the cases with MMP-2 1306 C/C genotype were significantly more susceptible for lymphatic and venous invasion than cases with $\mathrm{C} / \mathrm{T}$ or $\mathrm{T} / \mathrm{T}$ genotype, but they did not differ in the survival rate (33).

Eventually, Wang et al. examined the effect of glutamine-enriched nutritional support on intestinal mucosal barrier function, MMP-2, MMP-9, and immune function in patients with advanced gastric cancer during the perioperative chemotherapy. The results showed that after three cycles of treatment by adding glutamine, MMP-2 level was positively decreased (20).

Jiang et.al surveyed the effect of CDH17 on MMP-2 expression by NF- $\kappa \mathrm{B}$ pathway. Its results showed a positive relation; decreased or increased levels of MMP-2 was significantly regulated by $\mathrm{CDH} 17$ knockdown or overexpression, respectively. This effect was mediated by the NF- $\kappa \mathrm{B}$ pathway in GC cells. In the present study, GC tissues had a considerably higher level of CDH17 mRNA than the matched para-carcinoma tissues in the same patient. CDH17 expression was associated with clinical lymph node metastasis. $\mathrm{CDH} 17$ induce these activities through the NF- $\kappa \mathrm{B} / \mathrm{MMP}-2$ pathway (18).

Based on Deng et al. RAGE/ERK/Sp1/MMP2 pathway induced by glucose-derived AGEs (Advanced glycation end products) may result in GC progression and stimulating the invasion and metastasis of it. They found the accumulation of glucose-derived AGEs in cancer tissues and blood of GC patients and it's resulting in over-expression of RAGE, Sp1, and MMP2. This study revealed the following sequence: glucose-derived AGEs binding to RAGE, activating MEK1/2/ERK pathway, overexpression of Sp1, up-regulating MMP2 expression, and GC cells invasion, respectively (19).

\section{Conclusions}

In summary, our review indicated that increased MMP2 expression had been seen in gastric cancer. MMP-2 overexpression may play a crucial role in degrading ECM as well as stimulate angiogenesis and increase VEGF releasing. Therefore, MMP2 overexpression can play an important role in tumor metastasis, tumor size, invasion, and lymph node invasion in the GC. Furthermore, high-level expression of MMP-2 may be strongly associated with poor prognosis in GC patients. Thus, the detection of MMP-2 expression may serve as an independent prognostic factor for GC. In addition, MMP-2 polymorphism such as -1306C/T can be correlated with GC susceptibility. However, further studies with larger sample sizes and more comprehensive and meta-analysis data are still required for the achievement to conclusive results.

\section{Acknowledgments}

It is not declared by the authors.

\section{Footnotes}

Authors' Contribution: Kheirollah Yari designed the study, Fereshte Bibak and Samane Ahmadi had equal role and collected the data and wrote the first draft of the manuscript. Kheirollah Yari, Fereshte Bibak, Samane Ahmadi, Zeynab Khateri and Amirhossein Ahmadi read and approved the final manuscript.

Conflict of Interests: All the authors declare that they do not have a conflict of interest.

Funding/Support: This work was financially supported by a grant (No. 980067) from Office of the Vice-Chancellor for Research and Students Research Committee, Kermanshah University of Medical Sciences, Kermanshah, Iran.

\section{References}

1. Wang HL, Zhou PY, Zhang Y, Liu P. Relationships between abnormal MMP2 expression and prognosis in gastric cancer: A meta-analysis of cohort studies. Cancer Biother Radiopharm. 2014;29(4):166-72. doi: 10.1089/cbr.2014.1608. [PubMed: 24784911].

2. Fanelli MF, Chinen LT, Begnami MD, Costa WL Jr, Fregnami JH, Soares FA, et al. The influence of transforming growth factoralpha, cyclooxygenase-2, matrix metalloproteinase (MMP)-7, MMP9 and CXCR4 proteins involved in epithelial-mesenchymal transition on overall survival of patients with gastric cancer. Histopathology. 2012;61(2):153-61. doi: 10.1111/j.1365-2559.2011.04139.x. [PubMed: 22582975].

3. Yang Y, Xiong Y, Li J, Wu C, Jiang J. Association of TIMP-2-418G/C and TIMP-2-303G/A with gastric cancer: A meta-analysis. Onco Targets Ther. 2016;9:6801-8. doi: 10.2147/OTT.S114113. [PubMed: 27843330]. [PubMed Central: PMC5098565].

4. Moradi MT, Yari K, Rahimi Z, Kazemi E, Shahbazi M. Manganese superoxide dismutase (MnSOD Val-9Ala) gene polymorphism and susceptibility to gastric cancer. Asian Pac J Cancer Prev. 2015;16(2):485-8. doi: 10.7314/apjcp.2015.16.2.485. [PubMed: 25684475].

5. Nishizawa T, Suzuki H, Sakitani K, Yamashita H, Yoshida S, Hata $\mathrm{K}$, et al. Family history is an independent risk factor for the progression of gastric atrophy among patients with Helicobacter pylori infection. United European Gastroenterol J. 2017;5(1):32-6. doi: 10.1177/2050640616642341. [PubMed: 28405319]. [PubMed Central: PMC5384547].

6. Rugge M, Genta RM, Di Mario F, El-Omar EM, El-Serag HB, Fassan $\mathrm{M}$, et al. Gastric cancer as preventable disease. Clin Gastroenterol Hepatol. 2017;15(12):1833-43. doi: 10.1016/j.cgh.2017.05.023. [PubMed: 28532700].

7. Kazemi E, Kahrizi D, Moradi MT, Sohrabi M, Amini S, Mousavi SA, et al. Association between Helicobacter pylori hopQI genotypes and human gastric cancer risk. Cell Mol Biol (Noisy-le-grand). 2016;62(1):6-9. [PubMed: 26828979]. 
8. Hippo Y, Yashiro M, Ishii M, Taniguchi H, Tsutsumi S, Hirakawa K, et al. Differential gene expression profiles of scirrhous gastric cancer cells with high metastatic potential to peritoneum or lymph nodes. Cancer Res. 2001;61(3):889-95. [PubMed: 11221876].

9. Shahbazi M, Yari K, Rezania N. The first review study on association of DNA methylation with gastric cancer in Iranian population. Asian Pac J Cancer Prev. 2016;17(5):2499-506. [PubMed: 27268620].

10. Rahimi Z, Yari K, Rahimi Z. Matrix metalloproteinase-9 -1562T allele and its combination with MMP-2 $-735 \mathrm{C}$ allele are risk factors for breast cancer. Asian Pac J Cancer Prev. 2015;16(3):1175-9. doi: 10.7314/apjcp.2015.16.3.1175. [PubMed: 25735351].

11. Ganguly K, Maity P, Reiter RJ, Swarnakar S. Effect of melatonin on secreted and induced matrix metalloproteinase- 9 and -2 activity during prevention of indomethacin-induced gastric ulcer. J Pineal Res. 2005;39(3):307-15. doi: 10.1111/j.1600-079X.2005.00250.x. [PubMed: 16150113].

12. Luo Z, Dong X, Ke Q, Duan Q, Shen L. Downregulation of CD147 by chitooligosaccharide inhibits MMP-2 expression and suppresses the metastatic potential of human gastric cancer. Oncol Lett. 2014;8(1):3616. doi: 10.3892/ol.2014.2115. [PubMed: 24959277]. [PubMed Central: PMC4063597].

13. Miao X, Yu C, Tan W, Xiong P, Liang G, Lu W, et al. A functional polymorphism in the matrix metalloproteinase-2 gene promoter $(-1306 \mathrm{C} / \mathrm{T})$ is associated with risk of development but not metastasis of gastric cardia adenocarcinoma. Cancer Res. 2003;63(14):3987-90. [PubMed: 12873995].

14. Yari K, Rahimi Z, Moradi MT, Rahimi Z. The MMP-2 -735 C allele is a risk factor for susceptibility to breast cancer. Asian Pac J Cancer Prev. 2014;15(15):6199-203. doi: 10.7314/apjcp.2014.15.15.6199. [PubMed: 25124598].

15. Emara M, Cheung PY, Grabowski K, Sawicki G, Wozniak M. Serum levels of matrix metalloproteinase-2 and -9 and conventional tumor markers (CEA and CA 19-9) in patients with colorectal and gastric cancers. Clin Chem Lab Med. 2009;47(8):993-1000. doi: 10.1515/CCLM.2009.212. [PubMed:19569980].

16. Arcone R, Palma M, Pagliara V, Graziani G, Masullo M, Nardone $\mathrm{G}$. Green tea polyphenols affect invasiveness of human gastric MKN-28 cells by inhibition of LPS or TNF-alpha induced Matrix Metalloproteinase-9/2. Biochim Open. 2016;3:56-63. doi: 10.1016/j.biopen.2016.10.002. [PubMed: 29450132]. [PubMed Central: PMC5802102].

17. Zhang DY, Wang J, Zhang GQ, Chu XQ, Zhang JL, Zhou Y. Correlations of MMP-2 and TIMP-2 gene polymorphisms with the risk and prognosis of gastric cancer. Int J Clin Exp Med. 2015;8(11):20391-401. [PubMed: 26884955]. [PubMed Central: PMC4723800].

18. Jiang XJ, Lin J, Cai QH, Zhao JF, Zhang HJ. CDH17 alters MMP-2 expression via canonical NF-kappaB signalling in human gastric cancer. Gene. 2019;682:92-100. doi: 10.1016/j.gene.2018.05.042. [PubMed: 29783070].

19. Deng R, Mo F, Chang B, Zhang Q, Ran H, Yang S, et al. Glucosederived AGEs enhance human gastric cancer metastasis through RAGE/ERK/Sp1/MMP2 cascade. Oncotarget. 2017;8(61):104216-26. doi: 10.18632/oncotarget.22185. [PubMed: 29262634]. [PubMed Central: PMC5732800].

20. Wang J, Li Y, Qi Y. Effect of glutamine-enriched nutritional support on intestinal mucosal barrier function, MMP-2, MMP-9 and immune function in patients with advanced gastric cancer during perioperative chemotherapy. Oncol Lett. 2017;14(3):3606-10. doi: 10.3892/ol.2017.6612. [PubMed: 28927119]. [PubMed Central: PMC5588077].

21. Yao Z, Yuan T, Wang H, Yao S, Zhao Y, Liu Y, et al. MMP-2 together with MMP-9 overexpression correlated with lymph node metastasis and poor prognosis in early gastric carcinoma. Tumour Biol. 2017;39(6):1.0104283177004E+15. doi: 10.1177/1010428317700411. [PubMed: 28621235].

22. Donizy P, Rudno-Rudzinska J, Kaczorowski M, Kabarowski J, Fre- jlich E, Kielan W, et al. Disrupted balance of MMPs/TIMPs in gastric carcinogenesis-paradoxical low MMP-2 expression in tumor and stromal compartments as a potential marker of unfavorable outcome. Cancer Invest. 2015;33(7):286-93. doi: 10.3109/07357907.2015.1024316. [PubMed: 25965559].

23. Bornschein J, Seidel T, Langner C, Link A, Wex T, Selgrad M, et al. MMP2 and MMP7 at the invasive front of gastric cancer are not associated with mTOR expression. Diagn Pathol. 2015;10:212. doi: 10.1186/s13000015-0449-z. [PubMed: 26652716]. [PubMed Central: PMC4676863].

24. Chen Y, Huang Y, Huang Y, Xia X, Zhang J, Zhou Y, et al. JWA suppresses tumor angiogenesis via Sp1-activated matrix metalloproteinase-2 and its prognostic significance in human gastric cancer. Carcinogenesis. 2014;35(2):442-51. doi: 10.1093/carcin/bgt311. [PubMed: 24072772].

25. Huang Q, Lan F, Wang X, Yu Y, Ouyang X, Zheng F, et al. IL-1betainduced activation of $\mathrm{p} 38$ promotes metastasis in gastric adenocarcinoma via upregulation of AP-1/c-fos, MMP2 and MMP9. Mol Cancer. 2014;13:18. doi: 10.1186/1476-4598-13-18. [PubMed: 24479681]. [PubMed Central: PMC3937117].

26. Lukaszewicz-Zajac M, Mroczko B, Guzinska-Ustymowicz K, Pryczynicz A, Gryko M, Kemona A, et al. Matrix metalloproteinase 2 (MMP-2) and their tissue inhibitor 2 (TIMP-2) in gastric cancer patients. Adv Med Sci. 2013;58(2):235-43. doi: 10.2478/ams-2013-0018. [PubMed: 24384769].

27. Wang G, Wang W, Zhou J, Yang X. Correlation between telomerase activity and matrix metalloproteinases 2 expression in gastric cancer. Cancer Biomark. 2013;13(1):21-8. doi: 10.3233/CBM-130332. [PubMed: 23736018].

28. Partyka R, Gonciarz M, Jalowiecki P, Kokocinska D, ByrczekT. VEGF and metalloproteinase 2 (MMP 2) expression in gastric cancer tissue. Med Sci Monit. 2012;18(4):BR130-4. doi: 10.12659/msm.882614. [PubMed: 22460086]. [PubMed Central: PMC3560834].

29. Mroczko B, Lukaszewicz-Zajac M, Gryko M, Kedra B, Szmitkowski M. Clinical significance of serum levels of matrix metalloproteinase 2 (MMP-2) and its tissue inhibitor (TIMP-2) in gastric cancer. Folia Histochem Cytobiol. 2011;49(1):125-31. doi: 10.5603/FHC.2011.0018. [PubMed: 21526499].

30. Hwang TL, Lee LY, Wang CC, Liang Y, Huang SF, Wu CM. Claudin-4 expression is associated with tumor invasion, MMP-2 and MMP9 expression in gastric cancer. Exp Ther Med. 2010;1(5):789-97. doi: 10.3892/etm.2010.116. [PubMed: 22993603]. [PubMed Central: PMC3445934]

31. Wang LB, Jiang ZN, Fan MY, Xu CY, Chen WJ, Shen JG. Changes of histology and expression of MMP-2 and nm23-H1 in primary and metastatic gastric cancer. World J Gastroenterol. 2008;14(10):16126. doi: 10.3748/wjg.14.1612. [PubMed: 18330957]. [PubMed Central: PMC2693761].

32. Alakus H, Grass G, Hennecken JK, Bollschweiler E, Schulte C, Drebber $\mathrm{U}$, et al. Clinicopathological significance of MMP-2 and its specific inhibitor TIMP-2 in gastric cancer. Histol Histopathol. 2008;23(8):917-23. doi: 10.14670/HH-23.917. [PubMed: 18498066].

33. Wu CY, Wu MS, Chen YJ, Chen CJ, Chen HP, Shun CT, et al. Clinicopathological significance of MMP-2 and TIMP-2 genotypes in gastric cancer. Eur J Cancer. 2007;43(4):799-808. doi: 10.1016/j.ejca.2006.10.022. [PubMed: 17236757].

34. Mrena J, Wiksten JP, Nordling S, Kokkola A, Ristimaki A, Haglund C. MMP-2 but not MMP-9 associated with COX-2 and survival in gastric cancer. J Clin Pathol. 2006;59(6):618-23. doi: 10.1136/jcp.2005.033761. [PubMed: 16731602]. [PubMed Central: PMC1860392].

35. Zheng H, Takahashi H, Murai Y, Cui Z, Nomoto K, Niwa H, et al. Expressions of MMP-2, MMP-9 and VEGF are closely linked to growth, invasion, metastasis and angiogenesis of gastric carcinoma. Anticancer Res. 2006;26(5A):3579-83. [PubMed: 17094486].

36. Wu ZY, Li JH, Zhan WH, He YL. Lymph node micrometastasis and its correlation with MMP-2 expression in gastric carcinoma. World J Gastroenterol. 2006;12(18):2941-4. doi: 10.3748/wjg.v12.i18.2941. [PubMed: 16718824]. [PubMed Central: PMC4087816] 
37. Kubben FJ, Sier CF, van Duijn W, Griffioen G, Hanemaaijer R, van de Velde CJ, et al. Matrix metalloproteinase-2 is a consistent prognostic factor in gastric cancer. Br J Cancer. 2006;94(7):1035-40. doi: 10.1038/sj.bjc.6603041. [PubMed: 16538217]. [PubMed Central: PMC2361233].

38. Li JR, Qi FY, Li L. [Correlation between expression of matrix metalloproteinase-2 and angiogenesis in esophageal carcinoma]. Zhonghua Zhong Liu Za Zhi. 2005;27(2):96-8. Chinese. [PubMed: 15946548].

39. Ji F, Chen YL, Jin EY, Wang WL, Yang ZL, Li YM. Relationship between matrix metalloproteinase-2 mRNA expression and clinicopathological and urokinase-type plasminogen activator system parameters and prognosis in human gastric cancer. World J Gastroenterol. 2005;11(21):3222-6. doi: 10.3748/wjg.v11.i21.3222. [PubMed: 15929171]. [PubMed Central: PMC4316052].

40. Monig SP, Baldus SE, Hennecken JK, Spiecker DB, Grass G, Schneider PM, et al. Expression of MMP-2 is associated with progression and lymph node metastasis of gastric carcinoma. Histopathology. 2001;39(6):597-602. doi: 10.1046/j.1365-2559.2001.01306.x. [PubMed: 11903578].

41. Ji F, Wang WL, Yang ZL, Li YM, Huang HD, Chen WD. Study on the expression of matrix metallo proteinase-2 mRNA in human gastric cancer. World J Gastroenterol. 1999;5(5):455-7. doi: 10.3748/wjg.v5.i5.455. [PubMed: 11819490]. [PubMed Central: PMC4688622].

42. Allgayer H, Babic R, Beyer BC, Grutzner KU, Tarabichi A, Schildberg FW, et al. Prognostic relevance of MMP-2 (72-kD collagenase IV) in gastric cancer. Oncology. 1998;55(2):152-60. doi: 10.1159/000011850. [PubMed: 9499190].

43. Caenazzo C, Onisto M, Sartor L, Scalerta R, Giraldo A, Nitti D, et al. Augmented membrane type 1 matrix metalloproteinase (MT1MMP):MMP-2 messenger RNA ratio in gastric carcinomas with poor prognosis. Clin Cancer Res. 1998;4(9):2179-86. [PubMed: 9748137].

44. Mori M, Mimori K, Shiraishi T, Fujie T, Baba K, Kusumoto $H$ et al. Analysis of MT1-MMP and MMP2 expression in human gastric cancers. Int J Cancer. 1997;74(3):316-21. doi: 10.1002/(sici)10970215(19970620)74:3<316::aid-ijc14>3.0.c0;2-9. [PubMed: 9221811].

45. Sier CF, Kubben FJ, Ganesh S, Heerding MM, Griffioen G, Hanemaaijer $\mathrm{R}$, et al. Tissue levels of matrix metalloproteinases MMP-2 and MMP9 are related to the overall survival of patients with gastric carcinoma.BrJCancer.1996;74(3):413-7. doi:10.1038/bjc.1996.374. [PubMed: 8695357]. [PubMed Central: PMC2074643].

46. Nomura H, Fujimoto N, Seiki M, Mai M, Okada Y. Enhanced production of matrix metalloproteinases and activation of matrix metalloproteinase 2 (gelatinase A) in human gastric carcinomas. Int J Cancer 1996;69(1):9-16. doi: 10.1002/(SICI)1097-0215(19960220)69:1<9::AIDIJC3>3.0.CO;2-8. [PubMed: 8600068].

47. Karimi P, Islami F, Anandasabapathy S, Freedman ND, Kamangar F. Gastric cancer: Descriptive epidemiology, risk factors, screening, and prevention. Cancer Epidemiol Biomarkers Prev. 2014;23(5):700-13. doi: 10.1158/1055-9965.EPI-13-1057. [PubMed: 24618998]. [PubMed Central: PMC4019373]. 


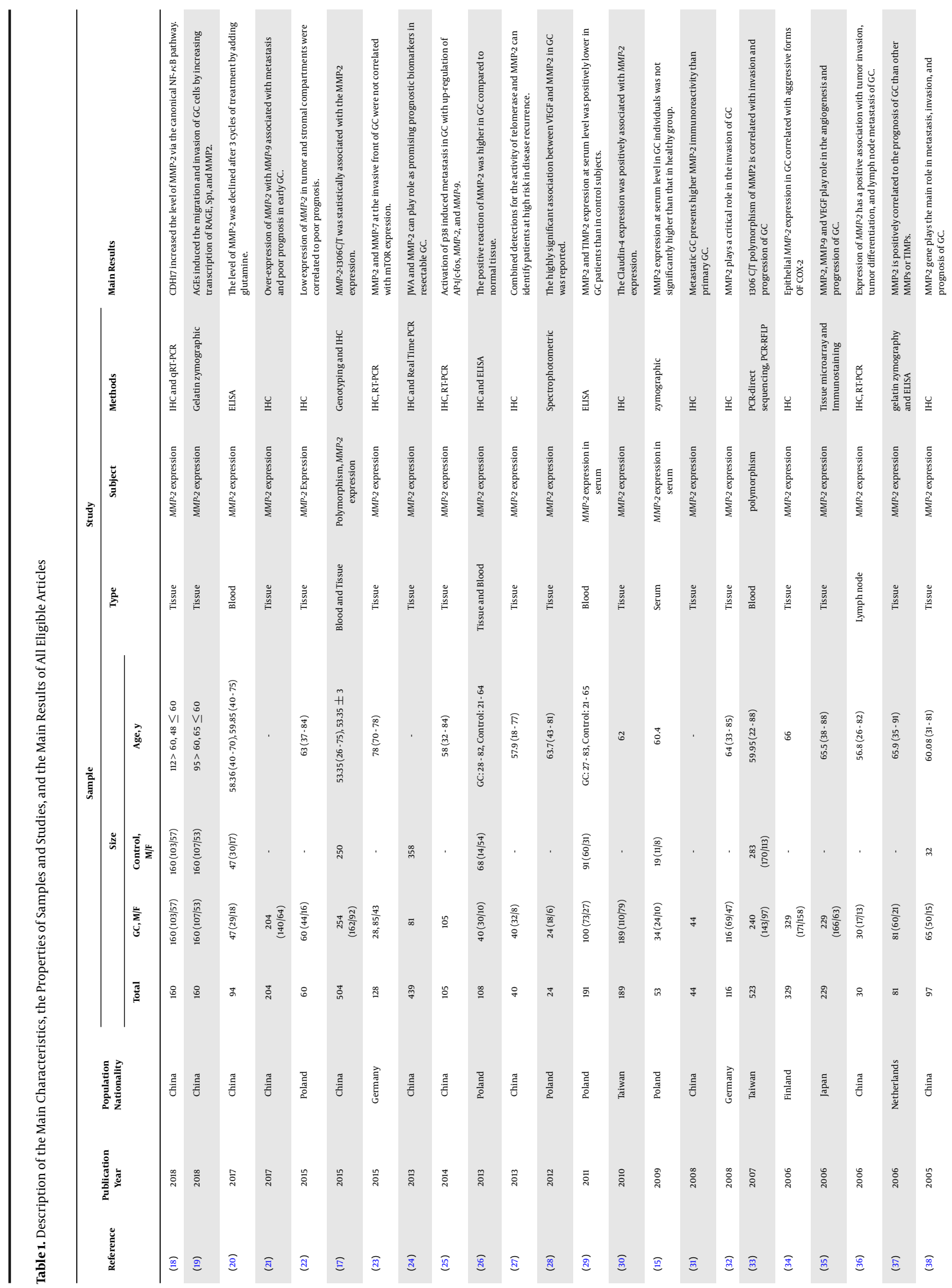




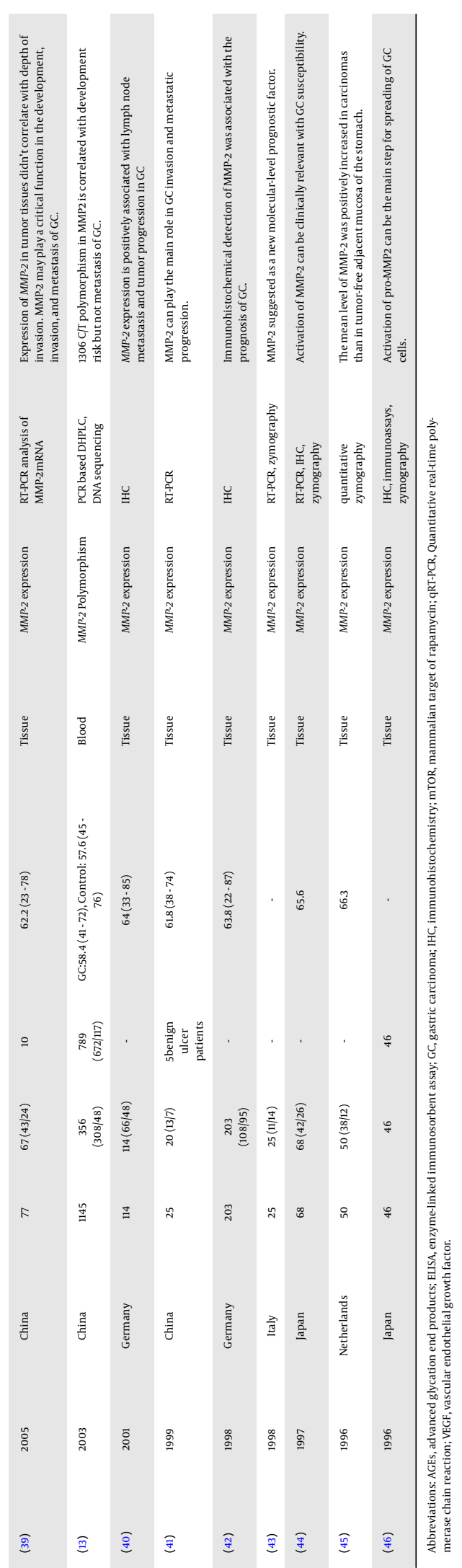

